\title{
Del Ferreyrazo al Partido Revolucionario de los Trabajadores. Un análisis de la trayectoria política de Gregorio Flores (1971- 1972)
}

From the Ferreyrazo to PRT. An analyses of the political trajectory of Gregorio Flores (1971-1972)

\begin{abstract}
Resumen: El presente artículo pretende analizar un aspecto sustancial de la vida y obra de Gregorio "Goyo" Flores tanto en su trayectoria individual como en su carácter de representante de una tendencia colectiva dentro de la clase obrera cordobesa y argentina. Solamente abordaremos su ingreso en las filas del Partido Revolucionario de los Trabajadores (PRT) entre 1971-1972. Consideramos que el ingreso de un militante a una organización partidaria es un proceso que no tiene un desarrollo lineal. Por el contrario, está marcado por múltiples contradicciones donde se expresan, por un lado, la paulatina comprensión por parte del sujeto de las ideas, programas y acciones del partido; y por el otro, las redes sociales que el agente va tejiendo, y que se reflejan en los vínculos políticos que establece con militantes y dirigentes de dicha organización.
\end{abstract}

Palabras clave: Trayectoria; Clase Obrera; Partido.

\begin{abstract}
This article aims to analyze a substantial aspect of the life and work of Gregorio "Goyo" Flores both in his individual career and in his character as representative of a collective trend within the Cordoba and Argentine working class. We will only address your entry into the PRT ranks between 1971-1972. We consider that the entry of a militant into a party organization is a process that does not have a linear development. On the contrary, it is marked by multiple contradictions where the gradual understanding of the party's ideas, programs and actions is expressed on the one hand; and on the other, the social networks that the agent is weaving, and that are reflected in the political ties that he establishes with militants and leaders of said organization.
\end{abstract}

Keywords: Trajectorie; Working Class; Party. 


\section{Introducción}

La clase obrera argentina, particularmente la cordobesa, ocupó un lugar importante en la historia del mundo del trabajo a lo largo del Siglo XX. La provincia de Córdoba en las décadas de 1960 y 1970 fue una suerte de laboratorio social y político que permitió la conformación de una vanguardia obrera que no solo se destacó por su combatividad, sino también por la forma en que expresó sus intereses de clase. Concretamente, se abrió camino una tendencia entre los operarios fabriles y de servicios (públicos y privados) que aplicó la metodología de protesta y deliberación, y tuvo como principal objetivo la defensa de la independencia política de la clase trabajadora en la lucha por un gobierno obrero y socialista. Con esta base programática, surgió una numerosa e importante camada de dirigentes obreros cuya influencia y autoridad no se limitó únicamente a su lugar de trabajo y/o sindicato, sino que llegaron a convertirse en una referencia para el conjunto del movimiento obrero.

El presente artículo pretende analizar un aspecto sustancial de la vida y obra de Gregorio "Goyo" Flores (1934-2011), tanto en su trayectoria individual como en su carácter de representante de una tendencia colectiva dentro de la clase obrera cordobesa y argentina. Flores fue, entre otras cosas, operario de la planta Fiat Concord, dirigente del Sindicato de Trabajadores de Concord (SiTraC) y militante, del Partido Revolucionario de los Trabajadores (PRT) entre los años 1972-1976 y del Partido Obrero (PO) en el período 1982-1993.

En este trabajo solamente abordaremos la trayectoria de Flores como militante del PRT. Consideramos que el ingreso a una organización partidaria es un proceso que no tiene nada de ser lineal o esquemático. Por el contrario, está marcado por múltiples contradicciones donde se expresan, por un lado, la paulatina comprensión por parte del sujeto de las ideas, programas y acciones del partido; y por el otro, las redes sociales que el agente va tejiendo, y que se reflejan en los vínculos políticos que establece con militantes y dirigentes de dicha organización. Siguiendo a FredericSawicki (2011), la constitución de una red nos permitirá erigir una suerte de 'entorno' creando un espacio simultáneo donde confluyen las trayectorias de los dirigentes del partido, militantes y simpatizantes en un contexto histórico determinado.

Indagar y reconstruir la trayectoria de un dirigente clasista nos obliga a abordar a la clase obrera desde su praxis, tanto en sus necesidades concretas, como en los diversos 
debates que tuvieron lugar, y que buscaban ofrecer una alternativa estratégica al régimen político imperante. En el caso de Flores, esto es particularmente importante ya que a lo largo de su vida encontramos múltiples tensiones que pusieron a prueba sus posicionamientos ideológicos. Coincidiendo con Bernard Pudal, para elaborar la biografía de un militante es necesario llevar a cabo un análisis "procesual" (PUDAL, 2011: 31) de su trayectoria, con el propósito de poder identificar, seleccionar y combinar los distintos aspectos y dimensiones de su acción. Creemos que el análisis de las intervenciones y escritos de Flores como militante del PRT nos permitirá identificar y comprender como una organización política se desenvuelve en la sociedad según una determinada época histórica. De esta manera, la simpatía o adhesión hacia una organización partidaria no constituyen una acción mecanicista, sino que expresan también un proceso consciente y 'vivo'.

Metodológicamente, el presente artículo estará estructurado de la siguiente manera: en primer lugar, analizaremos la intervención sindical y política de Flores en los hechos conocidos como el 'Ferreyrazo' y el 'Viborazo'. En segundo lugar, abordaremos su confinamiento en la cárcel, que constituyó un punto importante en su trayectoria. Para esto nos valdremos de fuentes primarias como la correspondencia del propio Flores. Por último, analizaremos el proceso de incorporación al PRT, que se consumó una vez liberado, el 14 de agosto de 1972.

Finalmente, nos centraremos en la relación dialéctica entre la acción individual del personaje y la acción colectiva, especialmente al interior de la organización que constituye el marco de su trabajo. En pocas palabras, elaboraremos la trayectoria de vida de un trabajador cuyo principal propósito fue transformar a su clase de objeto a sujeto de la historia.

\section{Del Ferreyrazo al Viborazo}

El 14 de enero de 1971, la empresa Fiat-Concord, en un acto de provocación, despidió a cuatro miembros de la comisión directiva y dos delegados del SiTraC, entre ellos, a Gregorio Flores. En asamblea y por unanimidad, se decidió ocupar la fábrica, tomar al personal gerencial como rehén y exigir la reincorporación de los cesanteados. Al día siguiente, la empresa tuvo que dar marcha atrás con los despidos. A su vez, la 
regional cordobesa de la Confederación General de Trabajadores (CGT) no presentó su solidaridad con la acción de lucha protagonizada por los obreros.

El triunfo de los operarios de Fiat fue el punto de partida para una serie de movilizaciones que van a ser llevadas a cabo por los choferes, empleados públicos y jubilados cordobeses exigiendo un aumento en los haberes. Asimismo, los operarios mecánicos pertenecientes a las principales plantas automotrices, como IKA-Renault, comenzaron a reclamar una serie de ítems, entre ellos la supresión de la insalubridad en secciones como forja y la inclusión de los premios de producción al salario básico. Con el objetivo de descomprimir y evitar una confluencia de los distintos reclamos obreros, la CGT decretó un paro para fines de enero, cuando comenzaban las vacaciones de gran parte de los trabajadores industriales. Más allá de las intenciones de la central sindical, el paro determinó la ruptura del "acuerdo social” entre la central obrera y el gobernador de Córdoba, Bernardo Bas, acelerando su renuncia. Esta situación abrió una crisis en la dirección regional de la CGT. Uno de sus integrantes, Elpidio Torres, renunció a la conducción del Sindicato Mecánico y Afines del Transporte Automotor (SMATA), en un cuadro de creciente repudio por parte de sus bases. El sector denominado "las 62 organizaciones" peronistas no podía concretar su reunificación, por lo tanto, en los hechos había una suerte de acefalia en la cúpula de la central gremial.

El triunfo de la ocupación de la planta de Fiat le había otorgado una importante autoridad a los sindicatos de Concord y Materfer. Su metodología de deliberación a partir de asambleas y sus acciones de lucha - en contraposición al resto de los gremios enrolados en la CGT- convirtieron al SiTraC-SiTraM en un punto de referencia para el resto de los trabajadores. A mediados del mes de febrero de 1971, durante un plenario de gremios se decidió la conformación de una 'Comisión de Lucha' compuesta por los principales gremios en ese momento, como la Unión Tranviaria Automotores (UTA), la Unión Obrera Metalúrgica (UOM), Luz y Fuerza (trabajadores del servicio eléctrico) y el SMATA. En términos generales, la Comisión de Lucha representaba prácticamente a la mayoría del movimiento obrero cordobés. Gregorio Flores, como representante del SiTraC, llevó el mandato de negarse a participar en la comisión. Se podría decir que esta posición podía considerarse extrema, teniendo en cuenta la crisis y el deterioro de la cúpula sindical. Vale decir que, hipotéticamente, la integración del SiTraC-SiTraM a la comisión, podría haber abierto la posibilidad de establecer una alianza con aquellos gremios que no adherían a las 62 Organizaciones, como Luz y Fuerza, e incluso con 
aquellos sindicatos que poseían una fuerte oposición de izquierda y una base combativa, como el caso del SMATA.

El 2 de marzo, en la Fiesta Nacional del Trigo en la ciudad de Leones, el nuevo gobernador de Córdoba, José Uriburu pronunció un discurso. Con la asistencia del presidente de la Nación, el General Levingston, el gobernador manifestó: "nadie ignora que la siniestra organización antiargentina que dirige a los que quieren dirigir la contrarrevolución, ha elegido a Córdoba [...] por definición se anida una venenosa serpiente cuya cabeza quizá Dios me depare el honor histórico de cortar de un solo tajo" (La Nación, 3 de marzo de 1971). Ante estas declaraciones, al día siguiente, se realizó un plenario de gremios en Córdoba. Agustín Tosco, secretario general del gremio de Luz y Fuerza, propuso como moción la toma simbólica de los establecimientos de trabajo de 10 a 14 horas. Casi la totalidad de los gremios presentes, principalmente aquellos enrolados en las 62 Organizaciones, apoyaron esta propuesta porque permitía que el conjunto de los trabajadores se quedara en sus lugares de trabajo y que no confluyesen en una sola movilización por el centro de Córdoba. En pocas palabras, no querían que se repitiese una nueva huelga política similar al Cordobazo de mayo de 1969 que precipitó en la renuncia del entonces presidente de facto, Juan Carlos Onganía. Los representantes de los sindicatos de Fiat rechazaron esta moción sin denunciar las intenciones de un importante sector de la central gremial. Sus argumentos básicamente se redujeron a una cuestión táctica, señalando divergencias en cuanto al carácter que debía tener la ocupación.

El 12 de marzo de 1971, los trabajadores de las plantas de Concord y Materfer realizaron un abandono de tareas y se dirigieron a un punto intermedio para realizar una medida de fuerza en conjunto. En ese mismo instante, la fuerza policial detuvo al párroco de la iglesia de barrio Ferreyra, que había apoyado activamente gran parte de las medidas de lucha de los trabajadores de la zona. Esta situación produjo una reacción del colectivo obrero, que se trasladó a los barrios aledaños a las fábricas. Con la presencia de tres mil personas aproximadamente, entre ellos trabajadores, estudiantes y vecinos, se realizó un acto público en la plaza de barrio Nicolás Avellaneda, y luego se decidió marchar y bloquear el tránsito en la Ruta 9. El intento de desalojo por parte de las fuerzas estatales produjo los primeros enfrentamientos con los manifestantes y la formación de barricadas a lo largo de la calzada. El resultado de la represión policial fue la muerte de un obrero, Adolfo Cepeda. Ante éstos hechos, la CGT cordobesa declaró un paro de 24 horas y convocó a un plenario para resolver nuevas medidas. El 
sepelio de Adolfo Cepeda se convirtió en un hecho político de magnitud, ya que asistieron casi 5000 personas. Esto reflejaba, no solo la indignación popular contra la represión estatal, sino que hacía evidente el repudio hacia el gobierno de facto. Las declaraciones de Uriburu, en un marco de crecientes luchas gremiales, actuaron como un catalizador en la radicalización de las movilizaciones obreras. Este proceso se pudo verificar en los acontecimientos de la semana del 11 de marzo, conocidos como el 'Viborazo'.

La CGT Córdoba llamó a continuar el paro activo hasta el 15 de marzo. El Sindicato de Empleados Públicos (SEP), la UOM y el SMATA, nuevamente llamaron a ocupar de manera simbólica los lugares de trabajo. La misma postura asumió Agustín Tosco, del sindicato de Luz y Fuerza, quien llamó a ocupar el área operativa ubicada en barrio Villa Revol. Su objetivo era que los trabajadores no marchasen con la columna del SiTraC-SiTraM que se dirigía al centro de la ciudad.

Durante la movilización, las columnas encabezadas por los obreros de Fiat, Perkins y GMD superaban las 7 mil personas. En la entonces llamada plaza Vélez Sarsfield se congregaron alrededor de 12 mil manifestantes. Luego, comenzó una suerte de guerra de consignas expresada en los siguientes cánticos: "ni golpe ni elección, revolución" vitoreada por militantes de Vanguardia Comunista y del Partido Comunista Revolucionario; "el pueblo unido jamás será vencido" entonada por miembros del Partido Comunista; "Perón y Evita, la patria socialista" por parte de Montoneros y la Juventud Peronista; y "lucha armada viva el Che Guevara" impulsada por las organizaciones políticas-armadas como el PRT-ERP (ARCHIVO SITRAC, 1971a). Entre los oradores, el primero fue Jorge Canelles del Partido Comunista, quien llamó “a la unidad de los trabajadores con la CGT" y a movilizarse en "solidaridad con la ocupación en Villa Revol y Agustín Tosco”. Luego intervino Gregorio Flores por el SiTraC: "Estamos por la destrucción del capitalismo. No podemos ocultar a los compañeros que el sistema que lo remplazará es el Socialismo [...] No estamos con los golpes ni tampoco con las salidas que pretenden ofrecer a la clase obrera" y se pregunta “¿A dónde están los dirigentes de la CGT?”. Luego siguió Mario Bagué del SMATA, quien justificándose afirmó que los dirigentes de la CGT “se encuentran ocupando los barrios", acción en la cual "debemos imitarlos, hay que ocupar Córdoba" (ARCHIVO SITRAC, 1971a). Después de las intervenciones comenzó una dispersión del grueso de la movilización hacia los barrios aledaños y el centro de la ciudad. A su vez, hubo sectores que se retiraron hacia Villa Revol y Barrio Güemes, entre otros destinos. 
Allí ocurrieron una serie de saqueos a comercios y supermercados. Estos hechos fueron relatados por Domingo Bizzi y Gregorio Flores, representantes del SiTraC, en un documental en el año 2014. Ambos coincidieron que durante el Viborazo se replegaron a barrio Guemes. Allí, los manifestantes saquearon un supermercado mayorista llamado "El Tabano". Sobre aquel episodio Flores relato: "cuestión que estaba un negro del PRT y se subió arriba y grito: 'Compañeros el pueblo ha expropiado este supermercado y vengan a llevar la mercadería' y los negros iban en carretilla, en carros y cargaban bolsas de azúcar, de todo" (DE MASCARÓ, 2014).

El Viborazo expresó parcialmente la disposición del proletariado cordobés a la acción directa. La contundencia del paro activo y la movilización le propinaron un revés al intento de un relevo militar 'ordenado' para resolver la crisis abierta por el Cordobazo. A esta conclusión arribó el propio Flores cuando afirmó: "no quedan dudas que esta lucha de la clase obrera y el pueblo fracturó o terminó de fracturar la cúspide del poder, porque la dictadura ya no era suficiente garantía para los intereses de la burguesía" (FLORES, 1994: 89). La provincia de Córdoba se había convertido en una suerte de centro político opositor a la dictadura militar. Según el semanario Panorama, existían tres tendencias principales que convergían en la dirección del movimiento obrero cordobés. La primera reflejada en "La Hora del Pueblo" que fue constituida por orden de Perón; la segunda la del Encuentro Nacional de los Argentinos (ENA), asociado principalmente al Partido Comunista1; y por último aquellos "núcleos obreros" que proponen como salida "un orden socialista" (PANORAMA, 1971: 14). Pero no debemos soslayar la dispersión del colectivo obrero reflejado en la 'guerra de consignas' y la desconcentración de los manifestantes que prosiguió con su posterior repliegue hacia los barrios donde transcurrieron los hechos anteriormente mencionados.

La crisis del régimen político le planteaba a un sector de las Fuerzas Armadas, encabezada por el General Agustín Lanusse, una única alternativa para garantizar el orden social vigente: preparar el retorno de Perón. Esto explica el "Gran Acuerdo Nacional" (GAN) impulsado por el gobierno. Este acuerdo implicaba un nuevo realineamiento de las fuerzas políticas donde, bajo las órdenes del propio Perón,

\footnotetext{
1"La Hora del Pueblo" fue un documento firmado el 11 de noviembre de 1970 por los partidos tradicionales como el Partido Justicialista, la Unión Cívica Radical, entre otros. El documento reclamaba por una mesa de negociación con la dictadura militar para establecer una 'transición democrática', a través de elecciones, y el surgimiento de un gobierno constitucional. El principal objetivo de "La Hora del Pueblo" era encorsetar la tendencia abierta por el Cordobazo y direccionarla hacia una salida bajo los intereses de la burguesía nacional. El "Encuentro Nacional de los Argentinos" fue una instancia de coordinación, creada en 1971, y formada principalmente por el Partido Comunista, el Partido Intransigente y el Partido Revolucionario Cristiano.
} 
quedaron estructuradas la dirigencia sindical y diversas agrupaciones peronistas. Aquellas organizaciones políticas, sindicatos o agrupaciones gremiales que no apoyaron esta salida sufrieron la represión del gobierno militar.

De esta manera, el gobierno militar desató una cacería sobre el activismo obrero cordobés. Luego del 15 de marzo, la provincia de Córdoba fue declarada Zona de Emergencia y se dictó la orden de captura para los miembros de la dirección del SiTraC. Estos últimos, decidieron desarrollar sus actividades en la clandestinidad y solamente concurrían a la planta por problemas puntuales. El 19 de marzo de 1971, Gregorio Flores se dirigió a la planta de Concord a garantizar que sus compañeros abandonasen sus tareas para apoyar el paro de 48 horas decretado por la CGT Regional. Antes de ir a la fábrica, accedió a una entrevista con una revista. Ante la pregunta ¿Cuándo un sindicato es `clasista’? dio la siguiente respuesta:

Cuando concibe a los trabajadores como una clase definida dentro del conglomerado social donde también existen otras clases [...] Quienes integran una corriente clasista están perfectamente esclarecidos sobre las naturales incompatibilidades de sus intereses de clase con aquellos propios de las clases dominantes. Hay clases explotadas que nada poseen, que deben vender su trabajo como una mercancía y allí se cuentan los obreros, empleados, campesinos pobres [...] del otro lado están los burgueses, oligarcas y terratenientes quienes detentan la propiedad de la tierra, grandes empresas y capitales financieros, es decir, los medios de producción y constituyen la clase explotadora. Los sindicatos clasistas, en el campo estrictamente gremial, conciben a los gremios como el gran frente único de la clase trabajadora y luchan para ponerlos al servicio de sus objetivos de clase. Esa tarea incluye necesariamente la diferenciación política de los trabajadores frente a las ideologías burguesas que pretenden inmovilizar la lucha de clases y por la vía de la conciliación perpetuar el injusto sistema social vigente (LOS LIBROS, 1971:13).

Saliendo con sus compañeros de trabajo, Gregorio Flores fue señalado por un guardia del establecimiento y es detenido por la policía Federal. Activistas y delegados gremiales principalmente pertenecientes al SiTraC-SiTraM, Luz y Fuerza y el SMATA, fueron también encarcelados y confinados en las penitenciarías de Devoto y 
Rawson. Mientras tanto, en el mes de agosto de 1971, Atilio López, secretario general de la UTA e integrante de la dirección de la CGT cordobesa, viajo a España a entrevistarse con Perón. Las directivas fueron claras: normalizar la central sindical y apoyar el Gran Acuerdo Nacional ${ }^{2}$.

\section{Su confinamiento en la cárcel: un laboratorio político}

Trasladado a los cuarteles militares, Gregorio Flores estuvo prestando declaración durante todo el día a distintos tribunales compuestos por la policía provincial, la federal, el ejército y el Servicio de Inteligencia del Estado (SIDE). Durante el último interrogatorio hubo un momento de tensión cuando un miembro de la SIDE le recriminó sus dichos acerca de que el ejército argentino estaba "al servicio del imperialismo”. Flores le contestó: “mire, yo no sé si están o no, pero concretamente: a mí me hace detener la Fiat, y la Fiat es imperialismo, y si el Ejército me detiene porque nosotros queremos ganar algo más porque luchamos por nuestras necesidades, y el ejército va y nos reprime, es porque el Ejército está al servicio del Imperialismo (LOS OBREROS, 1972: 3). Otro miembro del Tribunal le preguntó si era miembro de una organización de izquierda, a lo que Flores le respondió:

[...] nosotros luchamos porque en las fábricas existe una planta como forja con trabajo insalubre, y donde corresponde que trabajen seis horas, pero los compañeros tienen que trabajar nueve. Al cabo de uno a tres años, esos compañeros quedan con afecciones psíquicas, tienen alteraciones nerviosas tremendas, afecciones pulmonares, impotencia sexual, sorderas crónicas. Todo esto nosotros lo hemos comprobado con médicos que están al servicio de los obreros que han hecho todo un estudio de esos compañeros y certificaron que están completamente atrofiados. La empresa resuelve ese problema echándolos y dándoles 200.000 pesos de indemnización. Contra eso nosotros estamos luchando, le dije. Y luchamos porque la empresa viola los horarios de trabajo que establece la legislación, los ritmos de producción que son excesivos y agotan a los compañeros, peleamos

\footnotetext{
${ }^{2}$ En su regreso de Madrid, Atilio López afirmó: "No estamos dispuestos a que se intente importar ideologías extrañas a nuestra conciencia de argentinos, ni que tampoco aquellas que hablan que no quieren ni golpe ni revolución y quieran enseñarnos que es combatir" (Córdoba, 20 de agosto de 1971).
} 
por la reducción de la jornada laboral; peleamos por los ritmos de producción que a través de los premios a la producción nos están robando dinero que nos pertenece. Por abolir todo eso estamos luchando. Lo concreto es eso y por eso ustedes nos persiguen (LOS OBREROS, 1972: 9).

Flores junto a otros detenidos quedaron a disposición del Poder Ejecutivo siendo trasladados al Penal de Neuquén el 21 de marzo de 1971. En conjunto elaboraron un comunicado en el que agradecieron el apoyo brindado por los trabajadores de Fiat. También se refirieron a los obreros como los "agentes históricos" llamados a "combatir para destruir este oprobioso sistema y posibilitar la construcción de una sociedad socialista" (ARCHIVO SITRAC, 1971d). Desde el sindicato, se dio comienzo a una campaña por la libertad de los sindicalistas detenidos y en Neuquén se formó una comisión de solidaridad que brindó apoyo material y moral a los presos. La estadía de Flores en el Penal de Neuquén fue muy breve y al poco tiempo fue trasladado a la cárcel de General Roca en la provincia de Río Negro.

El 22 de mayo de 1971, los sindicatos de Fiat lanzaron una convocatoria a un Congreso nacional de sindicatos combativos, agrupaciones clasistas, y obreros revolucionarios para tratar la situación del movimiento obrero y preparar un plan de lucha para fines del mes de agosto. En la declaración de convocatoria se esbozó un programa que excedía los límites de la lucha sindical, ya que tenía un carácter político más amplio. Esto último se puede visualizar con la consigna con la que concluye el documento: "ni golpe, ni elección...revolución" (ARCHIVO SITRAC, 1971b). Durante su confinamiento en General Roca, Flores recibió una serie de materiales de lectura, que incluían desde volantes y boletines del sindicato, hasta libros. Aprovechó su encierro para adquirir nuevos conocimientos y a la vez, reforzar y difundir "en el seno de mi clase la concepción marxistas-leninista" (FLORES, 1971b).

Mientras tanto, en la planta de Concord, el SiTraC declaró un plan de lucha por el reconocimiento del nuevo convenio colectivo de trabajo y un aumento de salarios en los meses de junio y julio. El resultado de las medidas de fuerza dejó como saldo un acuerdo por un incremento salarial de un $30 \%$. No obstante, quedaba por debajo de lo solicitado en un comienzo por el gremio, que exigía un aumento de entre el 35 y el 
$40 \%^{3}$. En cuanto al convenio, lograron el reconocimiento de 62 artículos, pero la empresa no reconoció la insalubridad de forja y otros reclamos pendientes. La lucha por la paritaria y el convenio dejó un sabor amargo en el colectivo obrero, dado que la sensación era que el acuerdo no había alcanzado sus expectativas ${ }^{4}$. Desde la cárcel, Flores envió una carta con un balance de lo sucedido expresando: "entre un buen convenio y una buena dirección, prefiero ésta última, por lo que mucho que se puede hacer para que el conjunto de los trabajadores marchemos con claridad y decisión hacia el objetivo central, que es la toma del poder por la clase obrera" (FLORES, 1971a). En la misma misiva denunció al Gran Acuerdo Nacional como "un dique de contención al avance pujante de las fuerzas revolucionarias" donde "tenemos la irrenunciable obligación de acelerar su muerte y sepultarlo para siempre” (FLORES, 1971a).

El 19 de agosto, Flores envió una carta saludando el llamado al Congreso del SiTraC-SiTraM, considerándolo:

De fundamental importancia para el desarrollo y la unión de las fuerzas políticas que desde una perspectiva revolucionaria deben asumir la responsabilidad de señalar cuál es la alternativa que deben adoptar las clases explotadas del país frente a las falsas opciones marcadas por el régimen. Pero especialmente, para él, esta instancia debía servir para comenzar de una la construcción de una "dirección clasista y revolucionaria (FLORES, 1971c)

En su correspondencia, dejaba en claro su pensamiento político ligado al marxismo. Esto se puede evidenciar cuando sostiene que el programa del SiTraCSiTraM debía dirigirse hacia "el gobierno obrero y popular" en transición "hacia el socialismo". De esta forma, su carta caracteriza al GAN como el rescate de "los partidos oligárquicos y proimperialistas" cuyo programa no logra satisfacer "las exigencias mínimas del pueblo oprimido". Por último, reivindica su pretensión de que ambos

\footnotetext{
${ }^{3}$ La exigencia del $35-40 \%$ se expresaba en un lado para contrarrestar la pérdida del poder adquisitivo de los trabajadores con la inflación anual. Por el otro, los sindicatos de Fiat pretendían alcanzar un salario equivalente a los operarios de IKA-Renault o Ford que eran los más altos de la industria. Esto se puede consultar en la nota (ARCHIVO SITRAC, 1971c:8)

${ }^{4}$ Según los activistas pertenecientes a Vanguardia Comunista, un sector de la dirección del SiTraC comenzó "a reconocer a López y Tosco" como dirección de la CGT Regional y "en colaboración con el GAN". Esta decisión de parte de aquel sector habría propiciado la aceptación de la propuesta salarial dado que todos los gremios habían firmado paritarias por 21-25\% (ARCHIVO SITRAC, 1971e) Dicho sector estaba compuesto principalmente por miembros de la Comisión Directiva y delegados pertenecientes a Peronismo de Base.
} 
sindicatos superasen su alcance territorial circunscripto solamente a las plantas de Fiat. Para eso era fundamental que los mecánicos recuperasen "el SMATA para ponerlo al servicio de la clase obrera" siendo un deber que a "todos nos corresponde" (FLORES, 1971c).

El Congreso del SiTraC-SiTraM se celebró el 28 de agosto. El evento duró dos días y contó con la presencia de delegaciones gremiales provenientes principalmente de Córdoba, Capital Federal, Tucumán y Gran Buenos Aires. El documento presentado por las direcciones de los sindicatos de Fiat tenía como principal objetivo el de la extensión de su experiencia a todo el país a partir de la estructuración de una tendencia nacional clasista e independiente en el movimiento obrero (ARCHIVO SITRAC, 1971f). Básicamente, el documento establecía una serie de elementos que lo constituía en un programa diferente al elaborado por la CGT Nacional en La Falda (1957) y Huerta Grande (1962). Al congreso no asistieron los sindicatos independientes, como fue el caso de Luz y Fuerza, al igual que las corrientes sindicales orientadas por el Partido Comunista y Montoneros. El debate en su interior fue catalogado como diletante y desgastante. Esta situación tenía un solo propósito: la negativa de un sector de las organizaciones participantes a votar por el documento. Solamente los representantes gremiales del Partido Socialista de los Trabajadores (PST) y de Política Obrera votaron el documento final, el cual terminó siendo retirado por las directivas del SiTraCSiTraM. Gregorio Flores reconoció las vacilaciones de las comisiones directivas de los sindicatos de Fiat, que iban desde posiciones conciliadoras a otras netamente de carácter ultraizquierdista. En sus memorias, relató que más allá de las confusiones y limitaciones, la intención del congreso fue: "organizar al movimiento obrero en una alternativa independiente del Estado y de los patrones. Quisimos ser un punto de referencia al menos para la vanguardia del movimiento obrero que no logró cristalizarse" (FLORES, 2004: 192).

A principios del mes de setiembre, Flores fue trasladado a la provincia de Chubut, precisamente al Penal de Rawson. Aquella cárcel era destinada principalmente a los considerados "criminales de guerra", y, en menor medida, a los presos por delitos comunes. Allí, compartió su confinamiento junto a miembros de diversas organizaciones políticas, quienes organizaron los pabellones, votaron sus delegados y se establecieron grupos de lectura, estudio y ajedrez.

El 26 de octubre, la Resolución $N^{\circ} 304 / 71$, firmada por Lanusse, decretaba la disolución de los sindicatos de Fiat, la cesantía de empleados municipales, 
principalmente aquellos que componían el "ala clasista" en su sindicato y la intervención -en paralelo con el despido de los miembros de la comisión directiva y delegados- del sindicato de empleados públicos. La reacción de los trabajadores no se hizo esperar: los obreros de Fiat primero se enfrentaron físicamente con el ejército y luego declararon una huelga de brazos caídos. Alrededor de 5000 empleados públicos se movilizaron contra la intervención de su gremio y las cesantías a los activistas. La represión gubernamental pretendía asestar un golpe definitivo al plan que había comenzado con la detención de Flores, Tosco y otros dirigentes gremiales. La CGT local solamente apoyó la lucha de los empleados públicos y de los operarios de Fiat por separado y votando medidas de fuerzas aisladas cuando se necesitaba una respuesta unificada. Esta metodología fue llevando a los operarios de Fiat a un desgaste que culminó con la pérdida de su representación sindical. La ausencia de la directiva en las plantas de Concord y Materfer propició la aplicación de un nuevo plan de restructuración que partió del despido de todo el cuerpo de delegados y activistas. Esta medida se efectivizó gracias a la permanencia del ejército en el interior de las fábricas.

La derrota de los trabajadores de Fiat no se puede circunscribir a una cuestión de táctica. Sino a la connivencia entre el gobierno nacional y la CGT cordobesa que pretendían eliminar a una corriente gremial que amenazaba con disputarle la dirección de la central obrera. La disolución de los sindicatos de Fiat, fue un temor que siempre estuvo latente en Gregorio Flores: "para llegar a ese extremo, la dictadura y la patronal" tuvieron que contar "con la complacencia de los eternos canallas que están infiltrados en el movimiento obrero con títulos de 'dirigentes 'para traicionar a los trabajadores" (FLORES, 1971d). Su denuncia iba dirigida tanto a la CGT nacional como a su regional cordobesa acusándolos de ser individuos que "se abrazan con Mor Roig"5 y "contribuyen a que el ejército de desocupados sea cada vez más numeroso, frenando las luchas" (FLORES, 1971d).

En su carta del 12 de diciembre, Flores envió como adjunto un documento de balance de la experiencia de los sindicatos de Fiat cuyo título es El pecado de ser clasista. Este documento presenta un recorrido histórico de las experiencias de lucha de los operarios de Fiat hasta alcanzar la dirección del SiTraC en el año 1970. Es decir, tiene la intención de colocar la experiencia del SiTraC-SiTraM dentro de la historia del movimiento obrero desde la Semana Trágica en 1919 a la fecha. No obstante, en su

\footnotetext{
${ }^{5}$ Arturo Mor Roig fue uno de los ministros durante la dictadura de Lanusse.
} 
escrito no menciona al Cordobazo. Esta omisión no tiene nada de fortuita, sino que reflejaba la ausencia, o la participación minoritaria, de los principales miembros del SiTRaC durante el 29 de mayo de 1969. Podemos considerar como hipótesis que aunque pasaron dos años entre el Cordobazo y la redacción de su balance sobre el SiTraC-SiTRaM, para Flores no existía un hilo de continuidad histórica entre ambos sucesos. Esto refleja que la comprensión de un evento o un proceso histórico constituyen una praxis entre las experiencias vividas y el aprendizaje del sujeto. También podríamos establecer un paralelismo con el balance que elaboró el PRT, que se publicó en su órgano de prensa, El Combatiente, el 19 de diciembre de 1971. Aquí tampoco se hizo alusión al Cordobazo, y solamente se remite a trazar la trayectoria del Sitrac-Sitram desde su recuperación en el mes de mayo de 1970, hasta su disolución en octubre de 1971. Para el PRT, fueron dos causas las que motivaron la disolución de los sindicatos de Fiat: su progresivo aislamiento con otros gremios y la presión de elementos provenientes de la pequeña burguesía como intelectuales y estudiantes (DE SANTIS, 2015: 483). En sus memorias en el año 2004, Flores coincidió con esta tesis, sosteniendo en que las comisiones directivas de ambos gremios no tuvieron:

una correcta política de alianza con los sindicatos independientes, por ejemplo, y por la dependencia con el peronismo de direcciones sindicales que comprendían la necesidad de ir construyendo una opción, pero se negaban a un enfrentamiento frontal con el peronismo. Aunque visto desde la cárcel, creo que estuvo mal encarado en cuanto se le dio prioridad a la concurrencia de la pequeña burguesía y el estudiantado, y no a dirigentes sindicales que tenían tal vez una práctica burocrática administrativa, pero con los cuales podía haberse llegado a acuerdos que nos posibilitara ir avanzando en la lucha contra la patronal y la burocracia y el Estado (FLORES, 2004: 192).

En su balance de 1971, Gregorio Flores llegó a la conclusión de que al SiTraCSiTraM lo disolvió una suerte de 'triple alianza' compuesta por el gobierno militar, la patronal y la burocracia sindical. En ese sentido, expresa que los sindicatos de Fiat constituyeron una alternativa clasista y revolucionaria, es decir, "un faro luminoso" al cual dirigieron sus miradas los obreros y estudiantes del país. Por último, dejó en claro su postura de denunciar: 
a la Hora del Pueblo, el ENA y todas aquellas falsedades que alimentan esperanzas en las distintas variantes de la salida eleccionaria $[\ldots]$ Nuestra lucha es prolongada y dura $[\ldots]$ Creo que todas estas experiencias nos ayudan a comprender la necesidad de agruparnos en organizaciones de vanguardia y de masas, fuera del control de las clases dominantes y el imperialismo, como única garantía para continuar la pelea hasta lograr la construcción de una sociedad socialista que posibilitará la liberación definitiva de los oprimidos (FLORES, 1971:14-16)

En cuanto a la lucha por la reincorporación de los despedidos y la restitución de la comisión directiva del SiTraC, el conflicto ingresó en un camino judicial constituido de trámites, audiencias y apelaciones ante las distintos Juzgados y Cámaras. Mientras tanto, desde afuera, los ex miembros del sindicato de Fiat-Concord trataban de reorganizar a los operarios de manera clandestina. Para levantar la moral de los activistas y operarios, se organizaban las lecturas de las cartas de los detenidos, como las de Alfredo Curutchet ${ }^{6}$ y Gregorio Flores.

El 21 de marzo de 1972, el PRT-ERP secuestró al gerente de Fiat, OberdanSallustro. Esto produjo una escalada de allanamientos y detenciones que no solamente se circunscribió a los activistas cercanos a los gremios de Fiat. Dentro de la planta, la empresa elaboró un petitorio de firmas exigiendo la liberación de su gerente, los operarios que no firmasen recibirían un apercibimiento de despido (ARCHIVO SITRAC, 1972a). En el medio de las negociaciones, la policía irrumpió con disparos en el domicilio donde se encontraba el funcionario de la patronal italiana. Sallustro murió por el impacto de una bala en su cabeza. La muerte del gerente de Fiat produjo una campaña mediática orientada contra los dirigentes de los sindicatos de SiTraC-SiTraM. En un comunicado del 25 de marzo, el SiTraC respondió que lo acontecido fue el resultado de la "política laboral de Fiat":

\footnotetext{
${ }^{6}$ Alfredo "Cuqui" Curutchet (1940-1974) fue el asesor letrado de los sindicatos de Fiat desde julio de 1970 hasta su disolución, por decreto del Poder Ejecutivo de la Nación, en octubre de 1971. Continuó su labor como abogado de los operarios y activistas despedidos por Fiat que reclamaban su reincorporación. El 10 de setiembre de 1974, Curutchet fue asesinado por la organización parapolicial Triple A. El hecho ocurrió semanas después que la Justicia de Córdoba fallara a favor de la reinstalación de Gregorio Flores en la planta de Concord.
} 
Hoy Fiat utiliza millones que nosotros le hacemos ganar para llenar las pantallas de TV de todo el país con las lágrimas de la Sra de Sallustro. ¿Quién ve las lágrimas de la madre (¡82 años!) de Gregorio Flores, obrero de Concord confinado desde hace un año en el Sur? Los hijos de Sallustro aparecen vestidos a la última moda, y reciben el consuelo de los millonarios del mundo ¿Qué comen los 7 hijos de Faustino López, obrero de Concord preso en Devoto, y cuanto sacrificio hacen sus compañeros de línea, a los que apenas alcanza el sueldo, para comprarles pan y remedios? (ARCHIVO SITRAC, 1972b).

En una carta firmada por Alfredo Curutchet y Gregorio Flores, ambos coincidían con el comunicado del SiTraC. Sostienen la defensa de la "independencia frente a la dictadura y a la patronal explotadora" despegándose "de todo lo que relacionaba" a la “vida y libertad de un señor explotador". Por lo tanto se debía seguir bregando "por la reincorporación de los despedidos" y "reafirmar la voluntad inquebrantable del sindicato" (CURUTCHET y FLORES, 1972). Para el PRT-ERP, las operaciones militares, entre ellas el secuestro del gerente de Fiat, realizadas durante el año 1972 fueron "golpes muy importantes contra el GAN" (DE SANTIS, 2015: 477). Pero de acuerdo al balance que trazó su Comité Central, dichas acciones no dieron como resultado el crecimiento en las filas de la organización. Sino todo lo contrario: "la dirección del Partido sigue debilitándose [...] las caídas en relación con Sallustro han ocasionado importantes bajas en cuadros" (DE SANTIS, 2015: 477).

Al estar confinados a más de mil kilómetros de la Ciudad de Córdoba, tanto Flores como Curutchet no pudieron visualizar la repercusión que tuvo la muerte de Sallustro en la lucha por las reincorporaciones y reconocimiento de los cargos gremiales de los obreros de Fiat. Se levantaron todas las instancias de negociación al respecto y comenzó a surgir en una fracción de los despedidos la idea de negociar sus indemnizaciones. El proceso de organización clandestina de la planta se vio obstruido por el incremento de las listas negras por parte de la patronal y los apercibimientos a aquellos trabajadores que discutieran a su jefe de sección o tuvieran alguna acción que la empresa considerase sospechosa. Después del secuestro de Sallustro, por razones de seguridad enviaron a varios dirigentes del PRT-ERP a Rawson. En esa instancia, Flores conoció a Mario Roberto Santucho, dirigente del PRT. A su vez, integró un grupo de 
estudio junto a Curutchet y Domingo Menna. En ese lapso, Flores analizó principalmente las obras de Lenin, Mao TseTung y algunos escritos de Guevara. Pero también debatieron en profundidad sobre la experiencia del SiTRaC-SiTraM.

Para Santucho, al igual que para el PRT, era importante la creación de "zonas liberadas" donde se "se desarrollará la lucha armada tanto en forma rural como urbana" (DE SANTIS, 2015: 302). En una entrevista del año 1994, Gregorio Flores reconocía que para tomar el poder político era necesario que la clase obrera recurriese al armamento. Sin embargo, no coincidía en que las 'zonas liberadas' o, según él, la "guerra de guerrillas" fuese la táctica que debiese adoptar el proletariado para tomar el poder porque no educaba al conjunto de los trabajadores. Flores proponía la formación "de cuadros obreros" que debían tener su lugar "en la fábrica" y que debían asumir la tarea de explicar al resto de los operarios el programa de la organización (POZZI, 1994: 10-11).

El 28 de abril de 1972, la lista marrón -un frente de agrupaciones nucleadas en el Movimiento de Recuperación Sindical (MRS)- obtuvo el triunfo en las elecciones por la seccional cordobesa del SMATA. Este hecho generó una repercusión en todo el movimiento obrero, y particularmente, entre el activismo del SiTraC-SiTraM. Flores afirmaba que la recuperación de la seccional del gremio mecánico, reflejaba la profundidad de la conciencia política en el proletariado de ese sector, que, a pesar de la derrota de las huelgas de 1970, logró recuperar su sindicato. A su vez, consideraba que ese logro constituía una lección para el activismo de los sindicatos de Fiat sobre importancia de la paciente labor de mantener la organización clandestina de las plantas. En un comunicado, escrito junto a otros detenidos, expresaron que el resultado de las elecciones del SMATA: "señala el alto grado de conciencia de clase y confianza en sus propias fuerzas alcanzado por los obreros cordobeses en el curso de las extraordinarias movilizaciones de los últimos años, especialmente desde el Cordobazo de mayo de 1969, pasando por los paros activos, ocupaciones de fábricas, el Viborazo y las luchas clasistas en Perdriel y Fiat" (ARCHIVO SITRAC, 1972c). Por último, para Flores, había que aprovechar la recuperación del sindicato mecánico para que desde los sindicatos de Fiat se iniciara una campaña por el ingreso al SMATA. Es decir, nuevamente insiste en la idea de confluir en un solo sindicato por rama. En el mismo sentido, advertía a sus compañeros sobre la posibilidad de que la empresa Fiat comience a "trabajar secretamente a favor de la UOM" (FLORES, 1972b) para otorgarle la personería gremial de las plantas de Concord y Materfer. 
Salvo por la cuestión de la lucha armada, Gregorio Flores adhirió al programa del PRT, aunque todavía no efectivizaba su incorporación. Coincidía especialmente con dos de los pilares programáticos de la organización: "la creación de un partido marxistaleninista" y "la conformación de un Frente de Liberación Nacional" (DE SANTIS, 2015: 309). En esta perspectiva, apoyó todas aquellas campañas políticas direccionadas a las organizaciones armadas, marxistas, peronistas y radicales en función de un frente común contra el GAN. Un claro ejemplo fue la campaña por la liberación de los presos acompañada del pedido de que todas las organizaciones políticas y sindicales alentaran a "articular un vasto frente obrero y popular antidictatorial que encare enérgicamente la solidaridad con los presos sociales y políticos" (CURUTCHET y FLORES, 1972).

Otro aspecto fundamental de su acercamiento con el PRT estuvo relacionado con la concepción del 'hombre nuevo' y aquellos principios reflejados en la 'moral revolucionaria' que debía tener todo militante en la lucha por la instauración del socialismo. Esto le permitió a Gregorio Flores tender un puente entre su experiencia en el ámbito sindical y combativo y con lo que él consideraba sus 'verdaderos ideales'. De esta forma, su modelo de militancia es aquel donde debía prevalecer el ascetismo y el sacrificio en función de una causa revolucionaria. Para ello, su formación cristiana constituyó un soporte en la elaboración de este pensamiento.

Tanto el 'Che' Guevara como el Viet-Cong constituían modelos de referencia para la construcción de una concepción del militante ligado en 'cuerpo y alma' a la causa de la revolución. Presos políticos vinculados al PRT elaboraron un material, en forma de boletín, titulado Gaviotas Blindadas. En su primer folleto, publicado en el mes de julio de 1972, podemos visualizar los elementos anteriormente descriptos:

Si queremos hacer nuevos Vietnam en América Latina, como quería nuestro Che, sepamos aplicar creadoramente a nuestra realidad las enseñanzas de la experiencia vietnamita no solo en la práctica de la estrategia y la táctica militar, de la educación ideológica y de la labor política, sino también y ante todo, en el campo de la moral revolucionaria ${ }^{7}$.

\footnotetext{
7 "La manera fundamental de proletarizarse de las organizaciones revolucionarias, es aumentar constantemente la proporción de obreros en sus filas, ganar crecientemente la proporción de obreros en sus filas, ganar crecientemente a los obreros de vanguardia que reflejan las auténticas virtudes de su clase. Y vale la pena repetir esta perogrullada porque hay muchos compañeros revolucionarios que aunque reconocen sinceramente esta necesidad en la teoría, no se esfuerzan consecuentemente en la práctica por llenar obreros las filas revolucionarias. Cuando las organizaciones revolucionarias están constituidas en su base y en su dirección por una clara mayoría de obreros, recién entonces habrán adquirido la madurez política para cumplir cabalmente su misión histórica" (DE SANTIS, 2015: 395)
} 
Gregorio Flores, no solo adhirió al contenido del boletín, sino que concebía al 'Hombre Nuevo' como el hombre proletario con conciencia de clase, dispuesto a entregar su vida a la causa revolucionaria y que debía encuadrarse en una organización política. También sostenía, junto al PRT, que una organización que se consideraba revolucionaria debía incorporar obreros en sus filas, lo que le permitiría construir una nueva moral basada en la labor colectiva, lejos de todo individualismo. En este sentido entendía:

Cuando uno llega a sentir como una necesidad la existencia de esa nueva sociedad, para que produzca un nuevo hombre, con una mortalidad más altruista, más entregada hacia la causa y el bienestar de todos cuando uno comprende que luchar por eso, con todos los riesgos que implica, significa haber conseguido la forma de ser feliz, entiendo que eso que ya no importa lo que puede ocurrir con uno mismo. Porque están absolutamente seguros de que nunca te podrán quebrar ni doblegar. ¿Qué podemos quedar en el camino? Evidentemente podrán suprimirnos físicamente, pero las ideas continuaran su curso (LOS OBREROS, 1972: 9).

\section{Su incorporación al PRT}

El 12 de agosto, Gregorio Flores junto a 32 detenidos fueron puestos en libertad. Habían pasado prácticamente 17 meses de reclusión. Al momento de su liberación, y en una entrevista, afirmó lo siguiente:

Creo que esta es la mejor manera de partir de las necesidades concretas de los trabajadores, encontrándoles respuestas y avanzando todos en conjunto. Pero ahí no termina todo; si realmente queremos construir el socialismo y acabar con este sistema, habrá que construir un partido revolucionario de los trabajadores. Y yo no creo que ese partido puede resolverse en una mesa donde se discuta un programa, donde se caracterice a la sociedad de determinada manera, donde se caracterice de qué modo se va a tomar el poder, pero donde los obreros no estén participando. Es decir, no creo que esto se pueda resolver si los propios trabajadores no han visto la necesidad de tener ese partido. A mí me parece que ese partido tiene que nacer de una 
necesidad de los trabajadores de tener el partido que los represente: el partido de la clase obrera (LOS OBREROS, 1972: 9).

Para Flores no podría existir el socialismo sin una organización revolucionaria que lo vehiculice. En otras palabras, ya suscribía a los planteos programáticos del PRT.

El lunes 14 de agosto, se presentó a trabajar a la planta de Concord, dado que en el momento de ser despedido, el 19 de marzo de 1971, él ya se encontraba preso en el sur del país. En una especie de acción política, Gregorio Flores, acompañado por distintas organizaciones políticas y sindicales, se acercó a la puerta de la planta de Concord. En ese instante, la empresa dio la orden de no dejarlo ingresar y le notificó su despido. Ante la ilegalidad de la situación, Flores comenzó un juicio laboral por su reinstalación que duró aproximadamente dos años. Por la tarde, en el local del SMATA Córdoba se desarrolló un acto en conmemoración por la liberación de los detenidos. Flores dijo unas palabras al respecto:

Venimos a continuar la lucha en la misma trinchera en la que nos arrancaron [...] a la cárcel fui denunciado al sistema de explotación [...] cuando vuelvo, pretendo volver a trabajar. Cuando fui ahí me entero que Fiat Concord me despidió "sin causa" [...] Una línea política no se puede sepultar por decreto, como pretendió el gobierno sepultar la clasista de SiTraC-SiTraM con la cancelación de sus personerías [...]SiTraC-SiTraM vieron canceladas sus personerías, porque propusieron la destrucción del sistema capitalista y la construcción de una sociedad socialista; porque reclamaron que la sociedad capitalista dividida en clases antagónicas y que no hay coexistencia pacífica posible entre los explotadores que pretenden aplastarnos y los explotados que luchamos por construir una sociedad justa [...] Denunciamos que en esa lucha los explotadores usan todas las armas: muchos a quienes dice que se lo libera solo son cambiados de cárcel. Y los infiltrados en las filas obreras y populares se prestan a que el régimen use a los presos como mercancía. Entonces entran en el negocio de usar a los presos para ceder reivindicaciones que no se buscan por la lucha. La dictadura guarda lo más conocido como último elemento para negociar; como por ejemplo Curutchet y Tosco [...] Los expresos clasistas venimos a reafirmar una actitud de compromiso al denunciar al GAN, que es igual a torturas, secuestros, asesinatos y 
prisión. Hay que tomar fuerzas: existe una sola clase social consecuentemente revolucionaria, capaz de dirigir el proceso liberador: bajo la dirección de la clase obrera hay que unir a todos los explotados para destruir al sistema capitalista y hacer florecer sobre sus ruinas a la sociedad socialista (ARCHIVO SITRAC, 1972d).

El 15 de agosto de 1972, comenzó un intento de fuga en el Penal de Rawson. Un grupo de militantes de Montoneros, Fuerzas Armadas Revolucionarias (FAR) y del PRT-ERP lograron escapar con dirección a Chile. Entre ellos se encontraban Roberto Santucho, Domingo Menna, Fernando Vaca Narvaja y Roberto Quieto. Un segundo grupo no logró concretar la fuga y fue capturado por las fuerzas militares. El 22 de agosto, los detenidos fueron trasladados a la Base Aeronaval Almirante Zar, en la ciudad de Trelew, y fusilados por el ejército. Este hecho se conoció como la "masacre de Trelew" y generó una repercusión a nivel nacional e internacional. Este acontecimiento impulsó un mayor acercamiento de Gregorio Flores hacia el PRT. Porque vio en ese episodio una acción perpetrada no solamente por el ejército bajo el mando del gobierno militar, sino que estaba orquestado desde "las oficinas de la CIA", es decir, desde el centro del imperialismo ${ }^{8}$. Al igual que en el caso Sallustro, para él la posición del gobierno fue la de anteponer la opresión del sistema capitalista sobre los trabajadores y el pueblo.

Cuando llegó a Córdoba, Flores junto con Eduardo Castelo, activista del SiTraM, concurrieron a una reunión en el domicilio de Mauro "Negro" Gomez, dirigente nacional del PRT y responsable político por el comité regional de la provincia de Córdoba (FLORES, 2006: 117). Allí en primera instancia resolvieron una campaña para la organización de los despedidos de las plantas de Concord y Materfer. Luego, pasaron a discutir su incorporación al partido. En dicha reunión, Gregorio Flores se transformó oficialmente en militante del Partido Revolucionario de los Trabajadores.

\footnotetext{
${ }^{8}$ Un año después, en un artículo para la revista Hombre Nuevo, Gregorio Flores afirmó: "los voceros del sistema intentan justificar este tipo de represiones como la única manera. Afirman, de "terminar con la violencia". Este problema de la violencia es necesario ubicarlo históricamente. La explotación es una forma de agresión. Y desde el momento mismo en que la sociedad se divide en clases, en que hay explotadores y explotados, opresores y oprimidos, hay en consecuencia, agresores y agredidos. Es decir, se genera violencia, pero desde arriba hacia abajo. Y esa violencia de los opresores, de la explotación agresora, genera a su vez la violencia de los oprimidos, de los explotados-agredidos. Una violencia justa y revolucionaria, porque es la única vía para eliminar definitivamente la violencia de la opresión-explotación" (FLORES, 1973: 11).
} 


\section{Conclusiones}

Parafraseando a la historiadora Florence Joshua, la militancia, o el "compromiso militante", es un proceso que se incrusta en el tiempo, y no de manera esquemática o lineal. Por lo tanto, la identidad militante o de clase es fruto de la interacción, la construcción y las tensiones entre los actores sociales convirtiendo la realidad del militante en una suerte de "renegociación permanente" (JOSHUA, 2015: 12). La adhesión por parte de Gregorio Flores al PRT de ninguna manera fue un proceso automático. Muy por el contrario, estuvo marcado por las propias tensiones del espacio social donde transcurrió su trayectoria. Un espacio social marcado por las relaciones sociales o las disputas políticas entre los actores que intervienen en un contexto histórico determinado.

A lo largo de este artículo pretendimos reconstruir la trayectoria de un dirigente obrero a partir de un proceso dinámico y contradictorio. De esta manera, la trayectoria política de Gregorio Flores, que incluyen su ausencia durante el Cordobazo, su participación en la recuperación de los sindicatos de Fiat, la ocupación de la planta de Concord, su intervención durante el Viborazo, su confinamiento en el Penal de Rawson y su acercamiento e incorporación al PRT se articula con el modo en que el propio Flores reflexiona sobre estos hechos y los detalló en sus memorias. En síntesis, nuestra tarea como historiadores consistió en mostrar claramente esta interacción con el objetivo de reconfigurar la memoria de un militante obrero en la conflictiva época histórica que le tocó transitar.

\section{Fuentes}

ARCHIVO SITRAC (1971a). "15 de marzo: un paso adelante en el camino al socialismo" Declaración de la Corriente "El Obrero", marzo, (Subarchivo No 18 Ficha $\mathrm{N}^{\circ} 1$ )

(1971b). "Declaración "SiTraC y SiTraM a los trabajadores y al pueblo argentino", 22 de mayo, (Subarchivo $\mathrm{N}^{\circ} 1$, Ficha $\mathrm{N}^{\circ} 4$ ).

(1971c). "Paritarias: no nos van a doblegar" en Boletín $N^{\circ} 2$ del SiTraC, junio de 1971 p. 8. (Subarchivo No 1, Ficha $N^{\circ} 3$ )

. (1971d). "Carta de Gregorio Flores y los presos de Neuquén" en Boletín "El Compañero" de la Agrupación "1 de mayo", Año III Nº7, junio de 1971 (Subarchivo $\mathrm{N}^{\circ} 20$ Ficha $\mathrm{N}^{\circ} 4$ )

. (1971e). "El maoísta" N², Boletín de la agrupación 14 de enero, 21 de julio (Subarchivo $\mathrm{N}^{\circ} 19$, Ficha $\mathrm{N}^{\circ} 36$. 
(1971f). "Proyecto de declaración del SiTraC-SiTraM", presentado al Congreso de Sindicatos Combativos, Agrupaciones Clasistas y Obreros Revolucionarios, 18 de agosto, Subarchivo 1, Ficha $\mathrm{N}^{\circ} 1$.

.(1972a). "Comunicado de prensa SiTraC", 23 de marzo, Subarchivo N¹, Ficha $\mathrm{N}^{\circ} 4$.

.(1972b). "SiTrac denuncia: Fiat miente", 25 de marzo de 1972, Subarchivo N¹, Ficha N4 p. 2.

.(1972c). "Compañeros obreros del SMATA", Penal de Rawson, 2 de mayo de 1972.

.(1972d). "Discurso del "Goyo" luego de ser liberado" s/f, Subarchivo 1, Ficha No5.

DE MASCARÓ (dir.) (2014).La Política sindical del PRT-ERP (Argentina). https://www.youtube.com/watch?v=xFJYyb2-P5I 47min 36seg

CURUTCHET Alfredo y FLORES Gregorio (1972).Carta para el SiTraC y Activistas del SiTraM, Penal de Rawson, 2 de mayo de 1972, (Archivo SiTraC- Biblioteca Popular de Bella Vista, Córdoba)

FLORES,Gregorio (1971a).Carta desde el Penal General Roca, 11 de junio de 1971, (Archivo SiTraC- Biblioteca Popular de Bella Vista, Córdoba)

(1971b).Carta desde el Penal General Roca, 18 de julio de 1971. (Archivo SiTraC- Biblioteca Popular de Bella Vista, Córdoba)

(1971c).Carta desde el Penal de General Roca. 19 de agosto de 1971 (Archivo SiTraC- Biblioteca Popular de Bella Vista, Córdoba)

(1971d).Carta desde el Penal de Rawson, 26 de diciembre de 1971 (Archivo SiTraC- Biblioteca Popular de Bella Vista, Córdoba)

. (1972b).Carta desde el Penal de Rawson, 27 de mayo, p. 1, (Archivo del SiTraC(Archivo SiTraC- Biblioteca Popular de Bella Vista, Córdoba)

LOS LIBROS (1971). "El Pensamiento del SiTraC, entrevista a Gregorio Flores", N²1, Argentina, Agosto, p. 13.

LOS OBREROS(1972)."Flores cuenta su presidio: el precio de una lucha sin tregua", $\mathrm{N}^{\circ} 6.2$ da quincena de agosto de 1972 p. 9.

PANORAMA (1971). "Córdoba: se necesita comisionado popular y de buena presencia", Argentina, 9 de marzo de 1971, pág. 14

\section{Referencias bibliográficas}

DE SANTIS Daniel (comp.) (2015).A vencer o Morir. PRT-ERP documentos. Tomo $\mathrm{N}^{\circ} 1$, Buenos Aires: Editora Guevarista.

FLORES, Gregorio (1971). El pecado de ser clasista, 26 de diciembre, Penal de Rawson: copia elaborada en forma manuscrita por el autor (Archivo SiTRaCBiblioteca Popular de Bella Vista, Córdoba)

.(1973). “Trelew: la violencia de los represores".Nuevo Hombre $\mathrm{N}^{\circ} 46,2 \mathrm{da}$ quincena de agosto, p.11.

(1994) SITRAC-SITRAM: Del Cordobazo al clasismo, Buenos Aires: Editorial Magenta.

.(2004). SITRAC-SITRAM: La lucha del clasismo contra la burocracia sindical. Córdoba: Editorial Espartaco.

.(2006). Lecciones de batalla: Una historia personal de los '70. 2 ed. Buenos Aires: Razón y Revolución.

JOSHUA, Florence (2015).Anticapitalistes. Une sociologiehistorique de l'engagement.Éditions La Découverte, Paris. 
POZZI Pablo (1994). Entrevista a Gregorio Flores, Ex dirigente sindical del Sitrac. Red Latinoamericana de Historia Oral (RELAHO), $21 \mathrm{p}$.

PUDAL, Bernard (2011). Los enfoques teóricos y metodológicos de la militancia. Revista de Sociología, 25, Universidad Santiago de Chile, Santiago de Chile, 1735.

SAWICKI Frederic (2011). Para una sociología de los entornos y de las redes partidarias.Revista de Sociología, 25, Universidad Santiago de Chile, Santiago de Chile, pp. 37-53.

Artigo recebido em 01de abril de 2020.

Aprovado em 20 de junho de 2020.

DOI: 10.12957/intellectus.2020.52503 